\title{
Impact of Carbohydrate Structure on Hydrated Smectite Nanopore Dynamics
}

\author{
SABRINA ESTELlE KELCH ${ }^{1,2}$ \& LUdMILla ARISTILDE ${ }^{2,3 *}$
}

${ }^{1}$ Dept. of Soil and Crop Sciences, School of Integrative Plant Science, Cornell University, Ithaca, NY 14853 USA

${ }^{2}$ Dept. of Civil and Environmental Engineering, Northwestern University, Evanston, IL 60208 USA

${ }^{3}$ Dept. of Biological and Environmental Engineering, Cornell University, Ithaca, NY 14853 USA

(*correspondence: ludmilla.aristilde@northwestern.edu)

Carbohydrates represent a prevalent class of organic compounds in soil matrices. Prior studies [1-3] have implicated the role of carbohydrates in soil mineral aggregation and soil water retention. Our recent research $[1$, 2] has shown that the adsorption of two common carbohydrates (glucose and cellobiose) to the prototypical smectite clay, montmorillonite (MONT), resulted in increased nanopore size and restructured water dynamics. Here we seek to unravel the interaction mechanisms and water retention dynamics in MONT nanopores populated with different carbohydrate types. We investigate four carbohydrates of different structural complexity: the monomer glucose, the dimer cellobiose, the linear polymer amylose, and the highlybranched polymer amylopectin. We use isotope-ratio mass spectrometry to obtain clay samples with carbon equivalent carbohydrate content. We identify adsorption sites using nuclear magnetic resonance measurements $\left({ }^{29} \mathrm{Si}\right.$ and $\left.{ }^{27} \mathrm{Al}\right)$. We investigate hydration dynamics using a combination of $\% \mathrm{RH}$ moisture-dependent X-ray

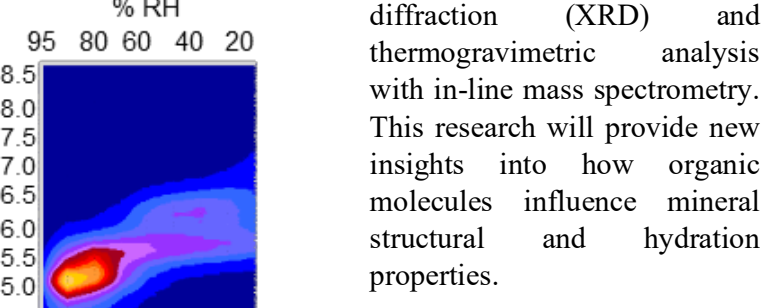

Figure 1. XRD profile intensity mapped across relative humidity (RH) for cellobiosepopulated MONT [1].

[1] Kelch et al. (2019) J. Phys. Chem. C 123 (47), 2881628827. [2] Aristilde et al. (2017) Adv. Water Resour. 106, 2438. [3] Carminati et al. (2010) Plant Soil 332, 163-176. 